\title{
Biomedical and Biopharmaceutical Research
}

\section{Research, Scientific Experiments Ethical Concerns and Portuguese Regulation}

Pesquisa, experiências cientificas, preocupações éticas e regulamento Português

\author{
Amilcar Roberto
}

CBiOS - Research center for Health Sciences \& Technologies, U. Lusófona, Campo Grande 376, 1749-024 Lisboa, Portugal

\begin{abstract}
Abstact
Disease and healing have been a motor for research along the times. It was first in the middle of the 19th century that ethical principles of scientific research in humans were defined by Claude Bernard (1865). In Portugal the "Conselho Nacional de Ética para as Ciências da Vida" (CNEV) was created by law in 1990 (Lei n. ${ }^{\circ}$ 14/90) to "Systematically analyse the moral problems roused by the scientific progression in the domains of biology, medicine or health in general". Animals have been also used in experiments and theirs rights are today regulated by law, in different extensions up to no human primates. European Union has the Directive 2010/63/EU for protection of animals used for scientific purposes, transposed to Portugal law by the Decreto-Lei n. ${ }^{\circ}$ 113/2013, being the "Direcção-Geral de Alimentação e Veterinária (DGAV)" the Portuguese authority that supervise the correct follow-up of the rules established in the law, including the authorization for use of no human animals in scientific research. Until the "Nuremberg Doctors Trial" several medical experiments were performed without question. Classical examples are experiments, involving humans on smallpox vaccine by Edward Jenner (1789); rabies vaccine by Louis Pasteur (1885) and yellow fever by Walter Reed (1900). In this trial was produced a number rules denominated "Permissible Medical Experiments", actually referred as the "Nuremberg Code", where the concept of informed consent was first approached. The Universal Declaration of Humans Rights (United Nations - 1948) and the Declaration of Helsinki - Ethical Principles for Medical Research Involving Human Subjects (World Medical Association - 1964) were not enough for impeding experiments such as Tuskegee syphilis experiment (1932 - 1972), Willowbrook (1950s) - mentally retarded children were deliberately infected with hepatitis virus, Jewish Chronic Disease Hospital (1960s) - live cancer cells were injected into 22 senile patients, Milgram (1963) - "Behavioral study of obedience" and Humphries (1970) - Tearoom Trade: Impersonal Sex in Public Places. Actually, the laws from many countries regulate the experiments involving humans including ethical exigencies. The European Union has the REGULATION (EU) No 536/2014 on clinical trials on medicinal products for human use, and repealing Directive 2001/20/EC, transposed to Portugal law by the Lei ${ }^{\circ} 21 / 2014$, being the "INFARMED - Autoridade Nacional do Medicamento e Produtos de Saúde, I.P." the Portuguese authority that supervise the correct follow-up of the rules established in the law.
\end{abstract}

\section{Lecturer's resumé}

$\mathrm{PhD}$ in Toxicology and Researcher, Uppsala University, 1981-2001- Associated Professor Universidade Lusofona de Humanidades e Tecnologias, 2001 


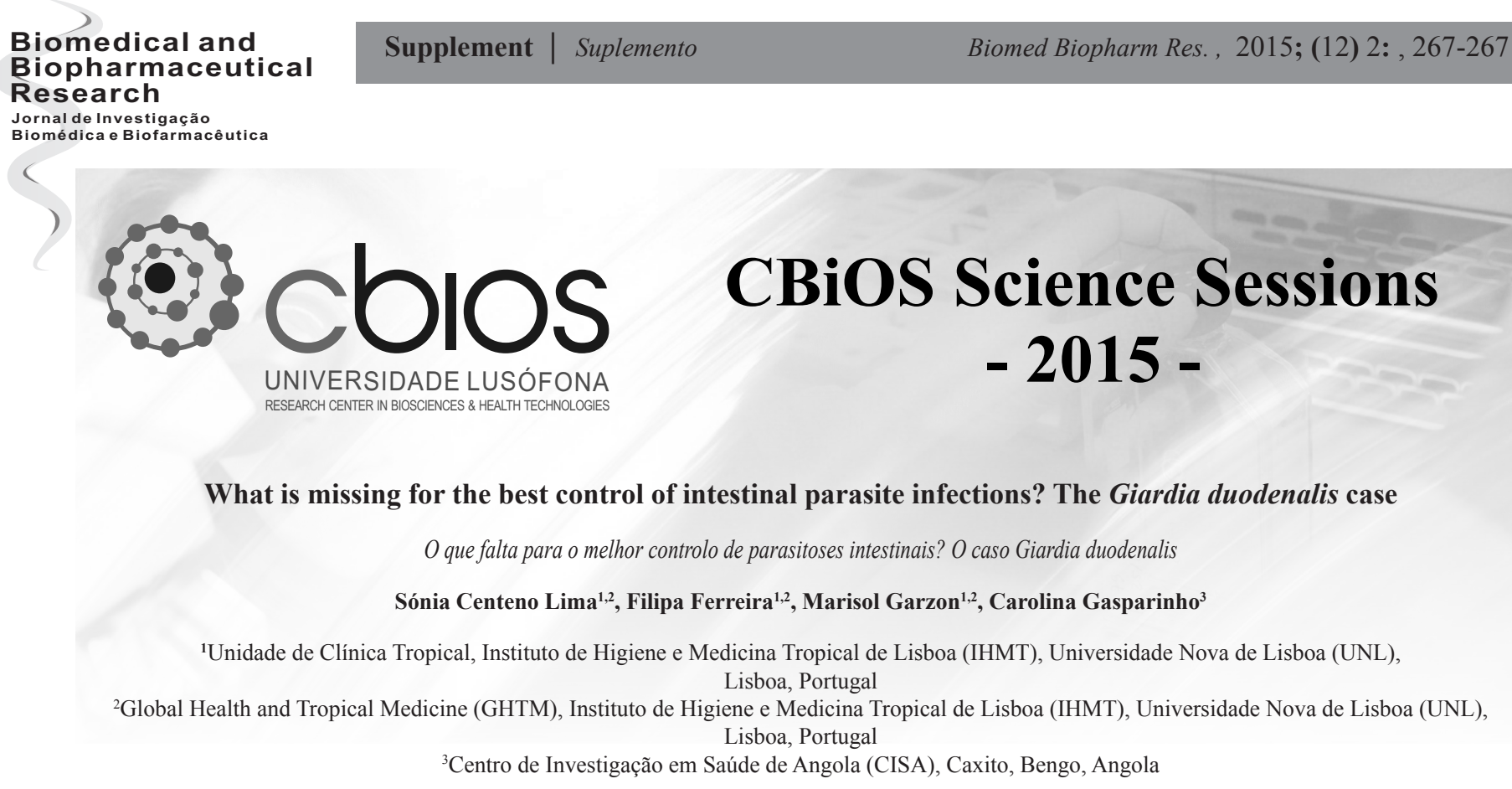

\begin{abstract}
Giardia duodenalis and soil-transmitted helminths are the most prevalent pathogenic intestinal parasites especially in developing countries and affecting particularly children.

While for soil-transmitted helminths strategies for its control are designed and implemented, such has not yet been clearly attained for Giardia duodenalis.

In the present science session, data obtained through community and hospital-based studies in Mozambique, São Tomé and Principe and Angola were presented. The results obtained support the importance of Giardia duodenalis infection in children and the urgent need to develop control strategies that target this protozoan together with soil-transmitted helminths.
\end{abstract}

\title{
Lecturer's resumé
}

Sonia Centeno Lima is a biologist, MSc in Health and Development and PhD in Biomedical Sciences. She is Assistant Researcher at the Tropical Clinic Unit/IHMT. Her current research work focuses on the epidemiology and control of intestinal parasites and malnutrition-infection in Angola, Mozambique, Portugal and Sao Tome and Principe. 